\title{
Trends in admissions, morbidity and outcomes at Red Cross War Memorial Children's Hospital, Cape Town, 2004 - 2013
}

\author{
Y Isaacs-Long, ${ }^{1} \mathrm{MB} \mathrm{ChB}, \mathrm{MPH} ; \mathrm{L}$ Myer, ${ }^{2} \mathrm{MA}, \mathrm{MPhil}, \mathrm{MB} \mathrm{ChB}, \mathrm{PhD} ; \mathbf{H} \mathbf{J}$ Zar ${ }^{3} \mathrm{MB} \mathrm{BCh}, \mathrm{FCPaed}(\mathrm{SA}), \mathrm{PhD}$ \\ ${ }^{1}$ Division of Epidemiology and Biostatistics, School of Public Health and Family Medicine, Faculty of Health Sciences, University of Cape Town, \\ South Africa \\ ${ }^{2}$ Division of Epidemiology and Biostatistics and Centre for Infectious Diseases Epidemiology and Research, School of Public Health and Family \\ Medicine, Faculty of Health Sciences, University of Cape Town, South Africa \\ ${ }^{3}$ Department of Paediatrics and Child Health, Red Cross War Memorial Children's Hospital and MRC Unit on Child and Adolescent Health, \\ University of Cape Town, South Africa
}

Corresponding author: Y Isaacs-Long (yumnah_isaacs@hotmail.com)

Background. Routinely collected patient information has the potential to yield valuable information about health systems and population health, but there have been few comprehensive analyses of paediatric admissions at South African (SA) hospitals.

Objectives. To investigate trends in hospitalisation and outcomes at Red Cross War Memorial Children's Hospital (RCWMCH), a major referral hospital for children in the Western Cape and SA.

Methods. Using routinely collected observational health data from the hospital informatics system, we investigated admissions between 2004 and 2013. Clinical classification software was used to group International Statistical Classification of Diseases and Related Health Problems 10th Revision (ICD-10) codes to rank causes during 2008 - 2013, when ICD-10 codes were widely available. Analyses examined trends in medical and surgical admissions over time.

Results. There were 215536 admissions over 10 years of 129733 patients. Admissions increased by 9.3\%, with increases in the general medical wards $(5 \%)$, medical specialty wards $(74 \%)$, the burns unit $(73 \%)$, and the intensive care unit (16\%). In contrast, admissions decreased in the trauma unit $(21 \%)$ and short-stay medical wards $(1 \%)$. In-hospital mortality decreased by $54 \%(p$-trend $<0.001)$ over 10 years. Diarrhoea and lower-respiratory tract illness were the most common causes for medical admissions, although admissions and deaths due to these conditions decreased between 2008 and 2013, which coincided with the national introduction of related vaccines. Similarly, tuberculosis admissions and deaths decreased over this period. These trends could be owing to a concurrent decrease in HIV comorbidity ( $p$-trend $<0.001$ ). Trauma was the most common reason for surgical admission.

Conclusion. Paediatric in-hospital mortality decreased consistently over a decade, despite an overall increase in admissions. Pneumonia and diarrhoea admissions decreased markedly over a 6-year period, but remain the most important causes of hospitalisation.

S Afr Med J 2017;107(3):219-226. DOI:10.7196/SAMJ.2017.v107i3.11364

Child health in South Africa (SA) has faced significant challenges in the recent past, largely as a result of poverty, over-burdened healthcare services, HIV and other infectious diseases. ${ }^{[1-3]}$ This dire situation recently saw an about turn, which was captured by an improving under-5 mortality rate (U5MR) ${ }^{[4]}$ - a sensitive indicator of child health - in response to health interventions targeting HIV, new vaccines, Integrated Management of Childhood Illness (IMCI), and other health policies aimed at promoting child health. ${ }^{[4,5]}$ However, latest estimates of the U5MR indicate that progress has stalled, with the U5MR hovering at 40 deaths/ 1000 live births ${ }^{[6]}-20$ deaths more than the Millennium Development Goal (MDG) target for 2015. ${ }^{[7,8]}$ Furthermore, as a national estimate, the U5MR cannot be disaggregated to inform locally at the district health service level, as it is precisely at this level that indicators of child health have to be appraised and addressed if further progress in child health is to be made. ${ }^{[5]}$

Hospital administrative databases are valuable repositories of clinical information that can provide important insights into the health needs of populations $s^{[9]}$ and can be used to develop locally relevant indicators of child health and wellbeing. ${ }^{[10]}$ Several international paediatric hospital database studies have highlighted various issues pertinent to child health. ${ }^{[11-15]}$ In SA, a recent analysis of a hospital database documented the burden on adult tertiary medical services in the Western Cape. ${ }^{[16]}$ At the Chris Hani Baragwanath Hospital, Johannesburg, SA, a series of studies used discharge data to detail HIV-related disease burdens in the hospital's paediatric medical wards. ${ }^{[17-19]}$ The Child Healthcare Problem Identification Programme (Child PIP), which uses detailed information of in-hospital child deaths in SA, provides important insights into the quality of paediatric healthcare in SA. ${ }^{[20]}$ However, analyses of high-quality paediatric hospital data remain scarce in SA, and few local studies document paediatric morbidity across medical and surgical causes.

Red Cross War Memorial Children's Hospital (RCWMCH), a major referral hospital for children of the Western Cape and SA, collects routine hospital information in an administrative database. The objective of this study was to examine mortality and morbidity trends and outcomes at RCWMCH as indicators of child health of the local population. In addition, the impact of recent changes in healthcare practices on child health at RCWMCH was also assessed.

\section{Methods}

Background

RCWMCH is a 283-bed paediatric referral hospital that provides tertiary and quaternary services for children $\leq 13$ years. The source population consists of children largely from the surrounding Western 
Cape health districts, who are referred from primary care services and district hospitals or transferred from other tertiary care units. There is no dedicated neonatal unit and the hospital does not provide obstetric services.

\section{Data source and elements}

RCWMCH uses the Clinicom patient information system (Health System Technologies, SA) to store data on admissions and discharges in two separate databases. This study is a descriptive analysis of observational, routinely collected health data available in the Clinicom database. Stored information includes demographic data, billing information, a variable indicating admission or internal transfer, activity dates, ward name, length of hospital stay, International Statistical Classification of Diseases and Related Health Problems 10th Revision (ICD-10) diagnostic codes (one primary, one subsidiary and 10 secondary diagnosis codes) and outcomes at discharge. The quality and reliability of data from this database are yet to be established.

We were unable to link the two datasets and therefore used the admissions dataset for all analyses except for length of hospital stay, for which we used the discharge dataset. The primary objectives were: $(i)$ to provide a description of overall admission trends across a decade; (ii) to describe mortality trends across a decade; and (iii) to rank, compare and describe trends in common admission diagnoses and cause-specific mortality. A secondary objective was to investigate the impact of HIV as a comorbid condition on the findings of our primary analysis.

\section{Statistical analyses}

We studied all admissions between 2004 and 2013 for the first two objectives. Changes in admissions were calculated as the percentage difference between 2013 and 2004

For the ranking of common diagnoses, only first admissions were considered to exclude readmissions for chronic conditions. There were no age exclusions. Primary ICD-10 diagnostic codes were grouped into 259 distinct clinical categories according to clinical classification software (CCS) (Healthcare Cost and Utilization Project, USA (HCUPUS)). ${ }^{[21]}$ This classification is widely used in database studies that analyse diagnostic trends. All original CCS codes were used in the rankings, except for the clinical entity lower-respiratory tract illness (LRTI), which was created by combining the codes for pneumonia, acute bronchitis, bronchiolitis, influenza and unspecified acute lowerrespiratory infection. Rankings were compared between 2008 and 2013, when ICD-10 codes were more complete.

For the analysis of disease patterns, all admissions for children under- 5 between 2008 and 2013 were included. The CCS category of pneumonia was maintained and that of intestinal infection which includes all infectious causes of diarrhoea - was reported as diarrhoea. The CCS category for HIV infection was searched for in all secondary diagnosis variables. All first admissions with a secondary diagnosis of HIV were included in this analysis.

Results were reported as frequencies, percentages or proportions; medians and interquartile ranges describe continuous variables. Precision of point estimates was determined by means of $95 \%$ confidence intervals (CIs). We computed the $\chi^{2}$ test for trend to assess significant changes in categorical variables over time. Wilcoxon tests or $t$-tests were computed to test for significant changes within continuous variables at the start and end of examined periods. All analyses were conducted using Stata version 12 (StataCorp., USA).

The University of Cape Town's Faculty of Health Sciences Human Research Ethics Committee approved the project (ref. no. 764/2014); permission was also obtained from the Hospital Research Review Committee of RCWMCH.

\section{Results}

\section{Admission and mortality trends}

From 2004 to 2013, there was a total of 215536 admissions to RCWMCH, accounted for by 129733 patients, with a median of 1 admission per patient during this period. Overall admissions increased by $9.3 \%$ (95\% CI 8.9 - 9.7) and mean monthly admissions increased by $9.3 \%$ (95\% CI $8.0-10.9 ; p=0.019)$ over a decade, while the number of new patients decreased by $8.6 \%$ (95\% CI $8.1-9.0$ ). Table 1 provides a general description of annual hospital admissions across the decade. Admissions to the general medical and surgical wards increased by $5 \%$ (95\% CI 3 - 6) and 9\% (95\% CI 8 - 10) over 10 years, respectively, but their contributions to total admissions remained proportionately the same. Admissions to the medical subspecialty wards increased by $74 \%$ (95\% CI $72-76)$, admissions to the burns unit increased by $73 \%$ ( $95 \%$ CI $70-76$ ), and admissions to the intensive care unit (ICU) increased by $16 \%$ (95\% CI 13 - 19) over the decade. Trauma unit admissions decreased by $21 \%$ (95\% CI $20-23$ ) and admissions to the short-stay medical wards decreased by $1.0 \%$ (95\% CI $0.8-1.2)$ across the decade.

The median age of admissions increased by 6 months over the 10 -year period $(z=-9.481 ; p<0.001)$. The general medical wards and ICU admitted younger patients, with a median age $<1$ year. Burns unit admissions had a median age of $\sim 2$ years, while the trauma unit and medical specialty wards admitted older children with an average age of 5 - 6 years (Supplementary Table $6^{*}$ ). The sex distribution remained largely unchanged over the decade, but with a consistent preponderance of male admissions (58\%). However, this percentage differed between specialties, with surgical wards and the trauma unit admitting proportionately more male patients than any of the other wards (Supplementary Table $6^{*}$ ).

The length of stay of medical admissions decreased from a median of 9 days in 2004 to a median of 7 days in $2013(z=9.13 ; p<0.001)$. The length of stay for surgical admissions remained constant across the decade at a median of 2 days.

Sixty-six percent of primary ICD-10 codes were missing from the dataset in 2004 compared with only $1.5 \%$ in 2013 . Acute care wards had a higher percentage of missing data over the 10-year period compared with other wards. Missing data were also associated with death, as data of patients who died were more likely to have missing ICD-codes than of those who survived $\left(\chi^{2}=156.289 ; p<0.001\right)$ (Supplementary Tables $7.1-7.4^{*}$ ).

Overall mortality decreased steadily across the decade by $54 \%$ $\left(\chi^{2}=179.42 ; p\right.$-trend $\left.<0.001\right)$, while the median age at death increased by 7 months over this period $(z=-2.578 ; p=0.01)$. The in-hospital mortality proportion in under- 5 children decreased by $58 \%$ across the decade from 32.4/1 000 in 2004 to 13.7/1 000 in 2013. Admissions to the ICU had the highest likelihood of death, whereas admissions to surgical wards (including trauma and burns units) had the lowest mortality (Supplementary Table $8^{\star}$ ).

\section{Common causes of morbidity and mortality}

There was a total of 11594 first medical and surgical admissions to RCWMCH in 2008 , of which 478 (4\%) had missing ICD-10 codes. In 2013, of the 9978 first medical and surgical admissions, only $144(1 \%)$ had missing ICD-10 codes. Common diagnoses were therefore compared across this 6-year period when missing ICD-10 data were minimal (Table 2). For medical admissions, diarrhoea or LRTI remained the top two reasons for hospitalisation, but they 
Table 1. Description of admissions to RCWMCH, January 2004 - December 2013

\begin{tabular}{|c|c|c|c|c|c|c|c|c|c|c|}
\hline Admissions & 2004 & 2005 & 2006 & 2007 & 2008 & 2009 & 2010 & 2011 & 2012 & 2013 \\
\hline Total admissions, $N$ & 19898 & 20238 & 21552 & 21432 & 21536 & 22880 & 22670 & 22645 & 20934 & 21751 \\
\hline New patients, $N$ & 12980 & 12875 & 13680 & 13329 & 13129 & 13874 & 13703 & 12728 & 11565 & 11870 \\
\hline $\begin{array}{l}\text { Admissions/month } \\
\text { (mean), } n\end{array}$ & 1658 & 1687 & 1796 & 1786 & 1795 & 1907 & 1889 & 1887 & 1745 & 1813 \\
\hline Age (years), median (IQR) & $\begin{array}{l}2.3(0.7- \\
6.2)\end{array}$ & $\begin{array}{l}2.4(0.8- \\
6.3)\end{array}$ & $\begin{array}{l}2.2(0.7- \\
6.1)\end{array}$ & $\begin{array}{l}2.0(0.7- \\
5.9)\end{array}$ & $\begin{array}{l}2.0(0.7- \\
5.6)\end{array}$ & $\begin{array}{l}2.1(0.7- \\
5.7)\end{array}$ & $\begin{array}{l}2.1(0.7- \\
5.7)\end{array}$ & $\begin{array}{l}2.6(0.9- \\
6.1)\end{array}$ & $\begin{array}{l}2.8(1.0- \\
6.4)\end{array}$ & $\begin{array}{l}2.8(1.0- \\
6.4)\end{array}$ \\
\hline Female, $n(\%)$ & $8313(42)$ & $8599(43)$ & $9245(43)$ & $9189(43)$ & $9017(42)$ & $9828(43)$ & $9559(42)$ & $9574(42)$ & $8865(42)$ & $9105(42)$ \\
\hline ICD-10 missing, $n(\%)$ & $13078(66)$ & $6470(32)$ & $7659(36)$ & $3811(18)$ & $772(4)$ & $640(3)$ & $755(3)$ & $629(3)$ & $437(2)$ & $328(1.5)$ \\
\hline \multicolumn{11}{|l|}{ Ward admissions, $n(\%)$} \\
\hline General medical & $745(4)$ & $701(3)$ & $636(3)$ & $702(3)$ & $663(3)$ & $744(3)$ & $703(3)$ & $594(3)$ & $658(3)$ & $779(4)$ \\
\hline Short-stay medical & 7667 (39) & $7677(38)$ & $8688(40)$ & $9239(43)$ & $9527(44)$ & $10258(45)$ & $9982(44)$ & $9112(40)$ & 7499 (36) & $7591(35)$ \\
\hline Medical subspecialty & $2117(11)$ & $2214(11)$ & $2405(11)$ & $2530(12)$ & $2689(12)$ & $2930(13)$ & $2866(13)$ & $3472(15)$ & $3387(16)$ & $3690(17)$ \\
\hline Surgical & 3359 (17) & $3482(17)$ & $3564(17)$ & $3458(16)$ & $3230(15)$ & 3299 (14) & $3202(14)$ & $3677(16)$ & 3488 (17) & $3658(17)$ \\
\hline Trauma unit & $2119(11)$ & $2094(10)$ & $1985(9)$ & $1635(8)$ & $1576(7)$ & $1614(7)$ & $1819(8)$ & $1774(8)$ & $1742(8)$ & $1667(8)$ \\
\hline ICU & $487(2)$ & $404(2)$ & $390(2)$ & $389(2)$ & $494(2)$ & $482(2)$ & $523(2)$ & $455(2)$ & $512(2)$ & $564(3)$ \\
\hline Burns unit & $693(3)$ & $786(4)$ & $899(4)$ & $906(4)$ & $891(4)$ & $940(4)$ & $1138(5)$ & $926(4)$ & $1026(5)$ & $1200(6)$ \\
\hline Day surgical & $2711(14)$ & $2880(14)$ & $2985(14)$ & $2573(12)$ & $2466(11)$ & $2613(11)$ & 2437 (11) & $2635(12)$ & $2622(13)$ & $2602(12)$ \\
\hline \multicolumn{11}{|l|}{$\begin{array}{l}\text { Length of stay (days), } \\
\text { median (IQR) }\end{array}$} \\
\hline General medical & $9(5-16)$ & $8(5-14)$ & $8(5-14)$ & $8(5-15)$ & $8(5-15)$ & $8(5-15)$ & $8(5-15)$ & $8(5-15)$ & $8(5-13)$ & $7(4-12)$ \\
\hline Surgical & $2(1-5)$ & $2(1-4)$ & $2(1-4)$ & $2(1-4)$ & $2(1-5)$ & $2(1-5)$ & $2(1-5)$ & $2(1-4)$ & $2(1-4)$ & $2(1-4)$ \\
\hline \multicolumn{11}{|l|}{ Deaths } \\
\hline $\begin{array}{l}\text { Total, } n \\
\text { (\% admissions) }\end{array}$ & $342(1.7)$ & $346(1.7)$ & $334(1.5)$ & $316(1.5)$ & $289(1.3)$ & $286(1.3)$ & $264(1.2)$ & $211(0.9)$ & $190(0.9)$ & $156(0.7)$ \\
\hline $\begin{array}{l}\text { Age (years), median } \\
\text { (IQR) }\end{array}$ & $\begin{array}{l}0.6(0.2- \\
2.2)\end{array}$ & $\begin{array}{l}0.5(0.2- \\
2.5)\end{array}$ & $\begin{array}{l}0.5(0.2- \\
1.9)\end{array}$ & $\begin{array}{l}0.7(0.2- \\
2.6)\end{array}$ & $\begin{array}{l}0.7(0.2- \\
3.5)\end{array}$ & $\begin{array}{l}0.8(0.2- \\
2.2)\end{array}$ & $\begin{array}{l}0.9(0.3- \\
4.2)\end{array}$ & $\begin{array}{l}1(0.2- \\
4.6)\end{array}$ & $\begin{array}{l}1.1(0.2- \\
5.3)\end{array}$ & $\begin{array}{l}1.2(0.3- \\
3.9)\end{array}$ \\
\hline Female, $n(\%)$ & $161(47)$ & $169(49)$ & $164(49)$ & $171(54)$ & $133(46)$ & $140(49)$ & $125(47)$ & $101(48)$ & $77(41)$ & $69(44)$ \\
\hline Under- $5 \mathrm{~s}, n / N$ & $293 /$ & $290 /$ & $284 /$ & $256 /$ & $228 /$ & $241 /$ & $205 /$ & $164 /$ & $140 /$ & $122 /$ \\
\hline & 13700 & 13725 & 14911 & 15201 & 15475 & 16374 & 16159 & 15607 & 13948 & 14460 \\
\hline Under-5, \% & 2.1 & 2.1 & 1.9 & 1.7 & 1.5 & 1.5 & 1.3 & 1.1 & 1.0 & 0.8 \\
\hline $\begin{array}{l}\text { Under-5 deaths/ } \\
1000 \text { under-5 }\end{array}$ & 32.4 & 32.5 & 28.8 & 25.5 & 22.5 & 22.5 & 19.4 & 16.9 & 16.1 & 13.7 \\
\hline Under-5, $n$ & $904)$ & 8935 & 9853 & 10033 & 10124 & 10712 & 10586 & 9732 & 8719 & 8898 \\
\hline
\end{tabular}

appear to be declining (Fig 1). Convulsions, which include epilepsy and febrile seizures, remained the third most common presentation. Tuberculosis (TB) was the fourth most common cause of medical admission in 2008, occurring more commonly in older age groups (Supplementary Table $9^{*}$ ), but decreased by $59 \%$ to 102 first admissions in 2013. Poisoning by medicines or drugs - prominent in the 1 - 5-year age group - also decreased over this period. Asthma admissions had increased owing to a marked rise in these admissions in older children (Supplementary Table $9^{*}$ ). Chronic obstructive pulmonary disease (COPD) and bronchiectasis first admissions increased markedly from 9 admissions in 2008 to 167 admissions in 2013. For surgical conditions, the most common presentations were for injuries (including fractures), followed by skin and subcutaneous tissue infections and tonsil disorders. There were no striking changes in the rankings for surgical conditions over the 6 years; however, injuries (calculated as the sum of injury diagnostic groups appearing in the top 10 rankings, i.e. other injuries and condi- tions due to external causes, upper limb fractures and lower limb fractures) appear to be increasing (Fig. 1). Congenital anomalies were most common in the youngest age category, while injuries and tonsil infections were more common in older age categories (Supplementary Table $10^{*}$ ).

Cause-specific mortality was explored by ranking the top 5 causes of death across this 6-year period (Table 3). Pneumonia, diarrhoea, sepsis and cardiac and circulatory congenital anomalies remained in the top 5 ranking for causes of death across this period. TB features among the top 5 causes of death for 2008, but is replaced in 2013 by the diagnostic grouping of unspecified injuries and conditions due to external causes; as a cause of death in 2013, this grouping entirely comprised the ICD-10 diagnosis of unspecified head injuries. The under-1-year age category experienced the largest decrease in mortality for this period (57\%), which was largely the result of a decline in deaths from diarrhoea, pneumonia and cardiac and circulatory congenital anomalies (Supplementary Table $11^{\star}$ ). In 2008, 
Table 2. Top 10 ranking of medical and surgical admissions at RCWMCH, 2008 and 2013

\begin{tabular}{|c|c|c|c|c|c|c|c|}
\hline \multicolumn{4}{|c|}{2008} & \multicolumn{4}{|c|}{2013} \\
\hline Rank & Disorder & $f$ & $\begin{array}{l}\text { Proportion of } \\
\text { hospitalisation, \% } \\
(95 \% \text { CI })\end{array}$ & Rank & Disorder & $f$ & $\begin{array}{l}\text { Proportion of } \\
\text { hospitalisation, \% } \\
(95 \% \mathrm{CI})\end{array}$ \\
\hline \multicolumn{8}{|c|}{ Medical (general medical and short-stay wards) } \\
\hline 1 & Diarrhoea & 2482 & $36(35-37)$ & 1 & LRTI & 1523 & $28(27-30)$ \\
\hline 2 & LRTI & 1936 & $28(27-29)$ & 2 & Diarrhoea & 1400 & $26(25-27)$ \\
\hline 3 & Convulsions & 488 & $7(6-8)$ & 3 & Convulsions & 371 & $7(6-8)$ \\
\hline 4 & TB & 249 & $4(3-4)$ & 4 & Meningitis & 221 & $4(4-5)$ \\
\hline 5 & Meningitis & 217 & $3(3-4)$ & 5 & Septicaemia & 213 & $4(3-5)$ \\
\hline 6 & Septicaemia & 214 & $3(2-4)$ & 6 & $\begin{array}{l}\text { COPD and } \\
\text { bronchiectasis }\end{array}$ & 167 & $3(3-4)$ \\
\hline 7 & $\begin{array}{l}\text { Poisoning by medicine/ } \\
\text { drugs }\end{array}$ & 132 & $2(1.6-2.3)$ & 7 & Asthma & 128 & $2(2-3)$ \\
\hline 8 & Asthma & 121 & $2(1.4-2.1)$ & 8 & Nausea and vomiting & 119 & $2(2-3)$ \\
\hline 9 & Other URTI & 96 & $1(1.1-1.7)$ & 9 & $\begin{array}{l}\text { Poisoning by } \\
\text { medicine/drugs }\end{array}$ & 116 & $2(2-3)$ \\
\hline 10 & Viral infection & 69 & $1(0.8-1.3)$ & 10 & Other URTI & 115 & $2(2-3)$ \\
\hline \multicolumn{2}{|c|}{ Total ICD-10 codes, $n$} & \multicolumn{2}{|c|}{6936 (missing 140) } & & & \multicolumn{2}{|c|}{5382 (missing 48) } \\
\hline \multicolumn{8}{|c|}{ Surgical (surgical wards, day surgery and trauma unit) } \\
\hline 1 & $\begin{array}{l}\text { Skin and subcutaneous } \\
\text { tissue infections }\end{array}$ & 460 & $11(10-12)$ & 1 & $\begin{array}{l}\text { Other injuries and } \\
\text { conditions due to } \\
\text { external causes }\end{array}$ & 628 & $14(13-15)$ \\
\hline 2 & $\begin{array}{l}\text { Other injuries and } \\
\text { conditions due to } \\
\text { external causes* }\end{array}$ & 372 & $9(8-10)$ & 2 & $\begin{array}{l}\text { Skin and } \\
\text { subcutaneous tissue } \\
\text { infections }\end{array}$ & 360 & $8(7-9)$ \\
\hline 3 & $\begin{array}{l}\text { Acute and chronic } \\
\text { tonsillitis }\end{array}$ & 325 & $8(7-9)$ & 3 & $\begin{array}{l}\text { Acute and chronic } \\
\text { tonsillitis }\end{array}$ & 355 & $8(7-9)$ \\
\hline 4 & Upper limb fracture & 309 & $7(7-8)$ & 4 & Upper limb fracture & 262 & $6(5-7)$ \\
\hline 5 & Abdominal hernia & 292 & $7(6-8)$ & 5 & Abdominal hernia & 236 & $5(5-6)$ \\
\hline 6 & Lower limb fracture & 211 & $5(4-6)$ & 6 & Lower limb fracture & 205 & $5(4-5)$ \\
\hline 7 & Other eye disorders & 197 & $5(4-5)$ & 7 & Other eye disorders & 193 & $4(4-5)$ \\
\hline 8 & $\begin{array}{l}\text { Other congenital } \\
\text { anomalies }\end{array}$ & 175 & $4(4-5)$ & 8 & $\begin{array}{l}\text { Other congenital } \\
\text { anomalies }\end{array}$ & 175 & $4(3-5)$ \\
\hline 9 & $\begin{array}{l}\text { Genito-urinary } \\
\text { congenital anomalies }\end{array}$ & 147 & $4(3-4)$ & 9 & $\begin{array}{l}\text { Genito-urinary } \\
\text { congenital anomalies }\end{array}$ & 156 & $4(3-4)$ \\
\hline 10 & $\begin{array}{l}\text { Other male genital } \\
\text { disorders }\end{array}$ & 135 & $3(3-4)$ & 10 & $\begin{array}{l}\text { Medical examination } \\
\text { or evaluation }\end{array}$ & 135 & $3(3-4)$ \\
\hline \multicolumn{2}{|c|}{ Total ICD-10 codes, $n$} & \multicolumn{2}{|c|}{4177 (missing 337) } & & & \multicolumn{2}{|c|}{4452 (missing 96) } \\
\hline
\end{tabular}

there were 10 deaths categorised as due to perinatal causes (Supplementary Table $11^{*}$ ).

\section{Diarrhoea and pneumonia in children}

Admissions to RCWMCH for all-cause pneumonia and diarrhoea in under- 5 children between 2008 and 2013 showed a consistent downward trend, particularly from 2010 onward (Table 4). The proportion of diarrhoea admissions per 1000 patients under- 5 decreased in 2013 by $33 \%(209.5 / 1000)$ compared with 2008 (313.7/1 000). Deaths due to diarrhoea also declined during this period - from a peak in 2009 $(n=43)$ to a low in $2013(n=9)$. The case fatality ratio (CFR) for diarrhoea dropped by $37.5 \%$ between 2008 and 2013 .

The figures for pneumonia followed a similar trend, with a $40 \%$ decline in the proportion of under-5 admissions from 2008 (185.8/1 000) to 2013 (110.7/1 000). Deaths due to pneumonia decreased between $2008(n=35)$ and $2013(n=12)$, with a reduction in the CFR of $37 \%$. The consistent downward trend in all-cause diarrhoea and pneumonia and the seasonal variation of these conditions are fur- 


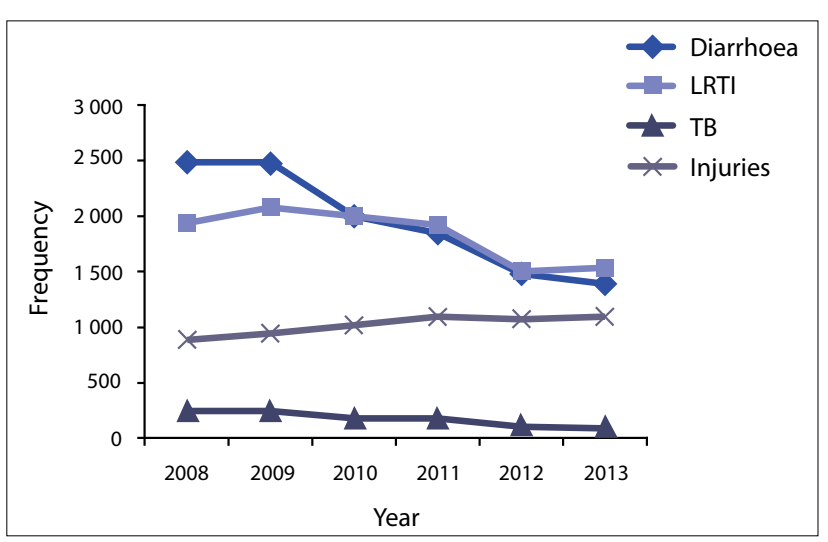

Fig. 1. Trends of common admission disorders at RCWMCH, 2008.

ther illustrated in Fig. 2. Both pneumonia and diarrhoea admissions showed distinct seasonal peaks, with diarrhoea admissions peaking in late summer/early autumn, while pneumonia admissions peaked in early winter.

\section{HIV comorbidity}

The first of 10 secondary diagnosis variables was explored to gain a sense of the completeness of the record of comorbidity (Table 5).
Although a similar trend of a decrease in missing data over time was observed, an average of $90 \%$ of secondary ICD-10 codes was missing between 2008 and 2013. An exploration of all secondary diagnosis variables nevertheless showed a consistent decrease in admissions with HIV comorbidity over a 6-year period. Annual admissions to RCWMCH from 2008 to 2013 with HIV comorbidity are given in Fig. 3.

\section{Discussion}

Overall admissions to RCWMCH increased by almost $10 \%$ between 2004 and 2013, with a concomitant increase in all ward admissions except in the short-stay medical wards and trauma unit. This increase in admissions could be the result of growth in the child population or to increased referrals from surrounding health facilities. However, there was a concurrent fall in the number of new patients, which indicates an increase in readmissions. Therefore, significant increases in admissions to medical specialty wards, ICU and the burns unit suggest an increasing prevalence of chronic or complex conditions, severity of disease, or conditions that require longer-term care, such as serious burns. Furthermore, the decrease in median length of stay in the general medical wards indicates a higher patient turnover, which, if due to bed pressure and early discharges, could result in more readmissions. A decrease in length of stay has been associated with a decreased threshold for admission, an increase in unplanned admissions or an increase in short-stay admissions, which is often a

Table 3. Top 5 causes of deaths at RCWMCH, 2008 and 2013

\begin{tabular}{|c|c|c|c|c|c|c|c|}
\hline \multicolumn{4}{|c|}{2008} & \multicolumn{4}{|c|}{2013} \\
\hline Rank & Cause of death & $f$ & $\begin{array}{l}\text { Proportion of all } \\
\text { deaths, } \%(95 \% \mathrm{CI})\end{array}$ & Rank & Cause of death & $f$ & $\begin{array}{l}\text { Proportion of all } \\
\text { deaths, \% }(95 \% \mathrm{CI})\end{array}$ \\
\hline 1 & Pneumonia & 42 & $15(11-19)$ & 1 & Sepsis & 17 & $11(6-17)$ \\
\hline 2 & Diarrhoea & 26 & $9(6-13)$ & 2 & Pneumonia & 12 & $8(4-13)$ \\
\hline 3 & $\begin{array}{l}\text { Cardiac and } \\
\text { circulatory } \\
\text { congenital } \\
\text { anomalies }\end{array}$ & 24 & $8(5-12)$ & 3 & $\begin{array}{l}\text { Other injuries and } \\
\text { conditions due to } \\
\text { external causes }\end{array}$ & 10 & $6(3-11)$ \\
\hline 4 & Sepsis & 14 & $5(3-8)$ & 4 & Diarrhoea & 9 & $6(3-11)$ \\
\hline 5 & TB & 12 & $4(2-7)$ & 5 & $\begin{array}{l}\text { Cardiac and } \\
\text { circulatory } \\
\text { congenital anomalies }\end{array}$ & 8 & $5(2-10)$ \\
\hline Total deaths, $N$ & & 289 & missing codes) & & & 156 & issing codes) \\
\hline
\end{tabular}

Table 4. All-cause diarrhoea and pneumonia in under-5 children at RCWMCH, 2008 - 2013

\begin{tabular}{|c|c|c|c|c|c|c|}
\hline & 2008 & 2009 & 2010 & 2011 & 2012 & 2013 \\
\hline \multicolumn{7}{|l|}{ Diarrhoea } \\
\hline Cases, $n$ & 3176 & 3146 & 2629 & 2421 & 1925 & 1864 \\
\hline Cases/1 000 patients $(n)$ & $313.7\left(\begin{array}{lll}10 & 124\end{array}\right)$ & $293.7(10712)$ & $248.3(10586)$ & $248.8(9732)$ & $220.8(8719)$ & $209.5(8898)$ \\
\hline Deaths, $n / N(\%)$ & $25 / 228(11)$ & $43 / 241(18)$ & $32 / 205(16)$ & $24 / 164(15)$ & $8 / 140(6)$ & $9 / 122(7)$ \\
\hline Case fatality ratio, $\%^{*}$ & 0.8 & 1.4 & 1.2 & 1.0 & 0.4 & 0.5 \\
\hline \multicolumn{7}{|l|}{ Pneumonia } \\
\hline Cases, $n$ & 1880 & 1976 & 1807 & 1664 & 989 & 985 \\
\hline Cases/1 000 patients $(n)$ & $185.8\left(\begin{array}{lll}10 & 124\end{array}\right)$ & $184.5(10712)$ & $170.7(10586)$ & $171.0(9732)$ & $113.4(8719)$ & $110.7(8898)$ \\
\hline Deaths, $n / N(\%)$ & $35 / 228(11)$ & $39 / 241(16)$ & $29 / 205(14)$ & $13 / 164(8)$ & $14 / 140(10)$ & $12 / 122(10)$ \\
\hline Case fatality ratio, $\%^{*}$ & 1.9 & 2.0 & 1.6 & 0.8 & 1.4 & 1.2 \\
\hline
\end{tabular}




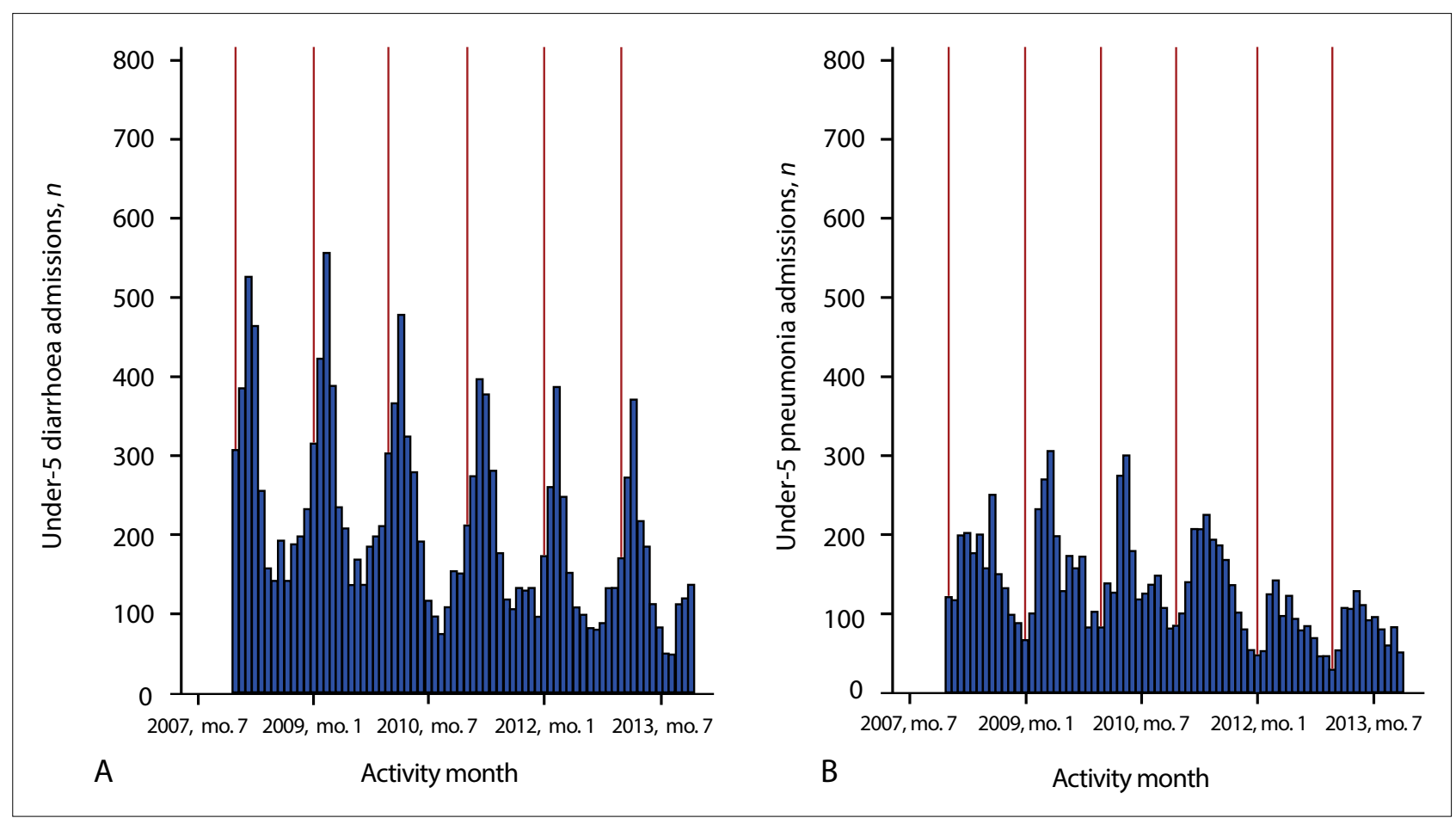

Fig. 2. Monthly admissions for (A) diarrhoea and (B) pneumonia in under-5 children at RCWMCH, 2008 - 2013. (Red reference line at month 1 (January) of each year.)

Table 5. Admissions to RCWMCH with HIV comorbidity, 2008 - 2013

\begin{tabular}{lllllll}
\hline \multicolumn{2}{l}{2008 - 2013 } \\
\hline Admission & $\mathbf{2 0 0 8}$ & $\mathbf{2 0 0 9}$ & $\mathbf{2 0 1 0}$ & $\mathbf{2 0 1 1}$ & $\mathbf{2 0 1 2}$ & $\mathbf{2 0 1 3}$ \\
\hline HIV & 124 & 172 & 71 & 70 & 42 & 31
\end{tabular}

consequence of primary healthcare inefficiencies. ${ }^{[12,13]}$ Conversely, a decrease in length of stay could be indicative of an improvement in quality of care, earlier access to care, or fewer cases of HIV, which is further supported by the consistent decline in in-hospital mortality observed across the decade.

A striking observation in the data is the preponderance of male admissions during the decade. The disparity in childhood morbidity between the sexes is a recognised phenomenon, with several studies having reported similar findings at various levels of care. ${ }^{[2-24]}$ Another striking finding is the increase in the median age of admissions and median age of deaths across the decade. The Baragwanath series of studies described a similar age effect, where the median age of paediatric admissions decreased during the early stages of the HIV pandemic. ${ }^{[17,18]}$ With progression of the pandemic and improvements in HIV management, an age reversal was noted, where HIV-infected patients were on average older than their uninfected counterparts and also experienced a dramatic decrease in mortality. ${ }^{[19]}$ Hence, the success of the prevention of mother-to-child transmission (PMTCT) campaign and availability of antiretroviral therapy (ART) could explain this age effect in the RCWMCH data, which is supported by the observed decrease in HIV comorbidity, and could also explain the marked reduction in TB cases within a span of 6 years. Alternatively, the increase in admissions to medical subspecialty wards and the burns unit, which generally admit older children, could also partially explain this finding.

Pneumonia or diarrhoea persists as the most common reasons for medical admissions, despite the observed reduction in cases

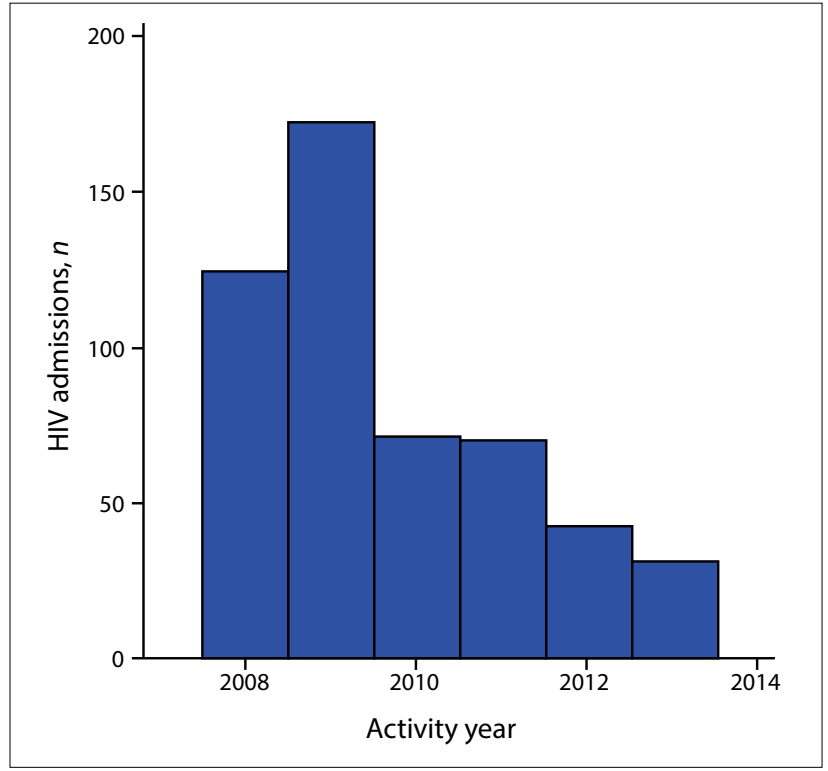

Fig. 3. Annual admissions to RCWMCH with HIV comorbidity, 2008 - 2013.

across the studied period. In 2009, the SA government made available the pneumococcal conjugate vaccine and rotavirus vaccine to all infants on a schedule informed by local vaccine efficacy studies. ${ }^{[25]}$ Subsequent studies of the public health impact of these vaccines have shown a beneficial effect. ${ }^{[25-27]}$ These data demonstrate a similar trend in the incidence and mortality of severe diarrhoea and pneumonia in under-5 children, which coincides with the introduction of new vaccines and may be due to an actual decline in population incidence and reduced severity of disease. However, other contributing factors, such as improvements in access to and treatment at lower levels of care, and improvements in access to 
safe water and sanitation, better nutrition, better hygiene practices, may contribute to such positive trends. ${ }^{[28]}$ Moreover, the recent decline in HIV transmission rates from mother to child in $\mathrm{SA}^{[29]}$ and expanding coverage of ART would impact on these diseases that occur commonly in immune-compromised patients. Pneumonia and diarrhoea admissions in this study demonstrated well-defined seasonal peaks that were consistent across a number of years. This finding is of particular interest from a health planning perspective, as healthcare services could be primed to cope with potential outbreaks during peak seasons.

In-hospital mortality at RCWMCH has declined consistently over a decade, mirroring the $\mathrm{U} 5 \mathrm{MR}^{[3,4]}$ and the national in-hospital mortality rate reported in the latest Child PIP publication. ${ }^{[30]}$ The cause-specific analysis of mortality demonstrates that this trend is largely owing to a significant decline in diarrhoea and pneumonia deaths in the infant population. Deaths caused by cardiac and circulatory congenital anomalies have also shown a sizeable reduction, which is most likely the consequence of advances in techniques for correcting congenital heart lesions. ${ }^{[31]}$ Of note too is the disappearance of TB as an important cause of death in children under- 5 and those $\geq 5$ years. Studies have demonstrated a high co-infection rate with $\mathrm{HIV}$ in children with $\mathrm{TB}^{[32,33]}$ and a higher mortality in HIV-infected children hospitalised with TB. ${ }^{[33]}$ Our data show that HIV comorbidity is declining, which could explain the decline in TB admissions and mortality; alternatively, improvements in detection and treatment at lower levels of care would also explain this trend. Important preventable causes of death, such as those due to injuries and burns, are becoming more prominent with the decline of certain infectious causes of childhood mortality. For further gains to be made in child mortality, these causes have to be addressed with equal vigour. Finally, the Western Cape mortality profile for 2012 reported that nearly $40 \%$ of all under-5 deaths occurred in the neonatal period. ${ }^{[34]} \mathrm{RCWMCH}$ does not have designated neonatal and obstetric services; however, in $2008,14 \%$ of under-5 deaths were in neonates, which increased to $16 \%$ in 2013 . The majority of neonatal deaths at RCWMCH were caused by congenital anomalies, other perinatal conditions or sepsis, whereas in the Western Cape in 2012 these were the result of prematurity, birth asphyxia and infections. ${ }^{[34]}$

\section{Strengths and limitations of the study}

Electronic hospital databases that contain clinical information have been described as 'a potential gold mine of information and knowledge, ${ }^{[9]}$ which this study has demonstrated in certain respects. Insights were gained into patient load, readmissions, and mortality indices that are indicators of health system functioning and provide guidance to allocate resources. The decreasing trend in mortality and possibly the decrease in hospital stay for general medical admissions suggest an improvement in quality of care. While a disproportionate increase in ward admissions implies an uneven increase in workload for the hospital, this information also indicates where extra staff and beds may be needed. The data also highlighted sustained downturns in pneumonia and diarrhoea admissions and HIV comorbidity, which confirm the success of relevant public health programmes. Additionally, this study identified matters of interest to future planning and research, such as the steady rise in burns and specialist medical admissions, the growing importance of injury-related admissions and deaths, and interesting trends in conditions such as TB and COPD/bronchiectasis.

An important limitation of any database study is the potential for error in recorded data, or in the omission of data, which has implications for the reliability of results. ${ }^{[35]}$ The quality of data in Clinicom has not been assessed for this study and therefore results should be interpreted with a degree of caution. Furthermore, we were unable to merge the two databases and therefore could not link admission and discharge information. Missing data were a problem in this dataset, as primary diagnostic codes were poorly recorded in the first half of the decade; however, these records improved substantially thereafter. Since missing codes were more common among acute care admissions, associated diagnoses were probably underestimated. Secondary diagnosis codes were largely absent from the database; considering that HIV infection appears to be strikingly under-reported we assume that this was owing to omission, presumably to these being admissions records. Therefore, HIV comorbidity reported here warrants a fair amount of circumspection; nevertheless, the general decline in HIV-associated disease is consistent with the strengthening of PMTCT and ART programmes. Likewise, this limitation also pertains to the assessment of diarrhoea and pneumonia, which occur commonly as comorbid conditions, but were explored only as primary diagnoses. This also raises the question about coding practices and how they influence disease and mortality trends, especially with regard to the reporting of sepsis as the primary diagnosis, when the underlying mechanism was diarrhoea or pneumonia.

A further limitation involves the ranking of common disorders, where only first admissions were considered; this nonspecific method of excluding readmissions for chronic conditions excluded all readmissions, even those cases admitted with new illnesses. This could affect the magnitude and the ranking of common diagnoses.

\section{Generalisability of findings}

Owing to the diverse objectives of this study, all results are not generalisable to a set population. $\mathrm{RCWMCH}$ policy is to provide services to children $<13$ years of age, but a substantial proportion of patients admitted were older. They were not excluded from the analysis, as they contributed to workload. Generalisability is more feasible when an analysis has clear age criteria, such as the trend analysis of diarrhoea and pneumonia admissions in under- 5 children. A caveat here though is that the neonatal population is not well represented owing to the paucity of services available for this age group. Furthermore, these data describe a population of children who were, firstly, ill enough to require hospital admission and, secondly, had access to these services. Nevertheless, the results do provide insights into the health of the population RCWMCH serves, even though it is not a population easily defined by rigid demographic criteria or geographical boundaries.

\section{Recommendations}

While the decrease in short-stay wards and trauma unit admissions suggests that less serious cases are being seen at lower levels of care, the decrease in length of stay in the general medical wards suggests an increase in unplanned and short-stay admissions. We recommend an evaluation of admission source, admission thresholds and referral criteria to ascertain the need for clearer guidelines for patient management at primary care level and at RCWMCH.

As a reliable information system is essential for health system strengthening, we recommend a validation study of Clinicom, that the two databases be linkable, and that hospital staff responsible for data recording and data capture be informed about the need for precision in these tasks.

We recommend further study of burns, injuries and chronic illness admissions, as these are increasing and require more of the hospital's 
resources. These and other findings of preventable conditions highlighted in this study - such as pneumonia and diarrhoea - could be used to shape policy on future prevention.

A subsequent study of coding practices is strongly recommended to clarify the effect of sepsis as a primary diagnosis on pneumonia and diarrhoea trends.

\section{Conclusion}

Hospital administrative databases are prone to error, but despite these inaccuracies they remain valuable data sources for high-quality health information. We observed some promising trends of special significance for child health in SA. There has been a consistent decline in in-patient mortality across a decade at RCWMCH, which suggests a general decline in childhood mortality in the catchment population. In addition, two major causes of childhood illness, pneumonia and diarrhoea, demonstrate a downward trend. However, they remain the most important causes of hospitalisation in childhood and efforts to reduce their burden should continue unabated.

*Supplemental material. Supplementary Tables 6 - 11 are available from the corresponding author on request.

Author contributions. YI performed all the analyses and drafted the manuscript. LM conceptualised the study, supported statistical analysis, interpretation of results and drafting of the final manuscript. HJZ provided input with conceptualisation of the study, interpretation of results and drafting of the manuscript.

1. Chopra M, Daviaud E, Pattinson R, et al. Saving the lives of South Africass mothers, babies, and children Can the health system deliver? Lancet 2009;374(9692):835-846. http://dx.doi.org/10.1016/S01406736(09)61123-5

2. Bamford L. Maternal, newborn and child health. In: Padarath A, English R, eds. South African Health Review 2012/13. Durban: Health Systems Trust, 2013:49-66.

3. Sanders D, Bradshaw D, Ngongo N. The status of child health in South Africa. In: Kibel M, Lake I Pendlebury S, et al., eds. South African Child Gauge 2009/2010. Cape Town: Children's Institute, Pendlebury S, et al., eds. South Af

4. Statistics South Africa. Millennium Development Goals, Country Report 2013. Pretoria: SSA, 2013:62-69. http://www.statssa.gov.za/wp-content/uploads/2013/10/MDG_October-2013.pdf (accessed 30 January 2017). McKerrow N, Mulaudzi M. Child mortality in South Africa: Using existing data. In: Fonn S, Padarath A eds. South African Health Review 2010. Durban: Health Systems Trust, 2010:59-71

6. Hall K, Nannan N, Sambu W. Children count - the numbers. In: De Lannoy A, Swartz S, Lake L, et al., eds. South African Child Gauge 2015. Cape Town: Children's Institute, University of Cape Town, 2015:100-134.

. Bryce J, Daelmans B, Dwivedi A, et al. Countdown to 2015 for maternal, newborn, and child surviva: The 2008 report on tracking coverage of interventions. Lancet 2008;371(9620):1247-1258. http://dx.doi. org/10.1016/s0140-6736(08)60559-0

8. Bhutta ZA, Chopra M, Axelson H, et al. Countdown to 2015 decade report (2000 - 2010): Taking stock of maternal, newborn, and child survival. Lancet 2010:375(9730):2032-2044. http://dx doi org/10.1016/ S0140-6736(10)60678-2

9. Safran C, Chute CG. Exploration and exploitation of clinical databases. Int J Biomed Comput 1995;39(1):151-156. http://dx.doi.org/10.1016/0020-7101(94)01094-h

10. Ben-Arieh A. The child indicators movement: Past, present and future. Child Indicators Res 2007;1(1):3-16 http://dx.doi.org/10.1007/s12187-007-9003-1
11. Chavez GF, Ellis AA. Pediatric hospital admissions for measles. Lessons from the 1990 epidemic. West J Med 1996;165(1-2):20-25

12. Hill AM. Trends in paediatric medical admissions. BMJ 1989;298(6686):1479-1483. http://dx.doi. org/10.1136/bmj.298.6686.1479

13. Saxena S, Bottle A, Gilbert R, et al. Increasing short-stay unplanned hospital admissions among children in England; time trends analysis '97-06. PloS ONE 2009;4(10):e7484. http://dx.doi.org/10.1371/journal. pone. 0007484

14. Connors C, Millar WJ. Changes in children's hospital use. Health Reports 1999;11(2):9-19.

15. Macy ML, Stanley RM, Lozon MM, et al. Trends in high-turnover stays among children hospitalized in the United States, 1993 - 2003. Pediatrics 2009:123(3):996-1002. http//dx doi org/10.1542/peds 2008-1428

16. Myer L, Smith E, Mayosi BM. Medical inpatient mortality at Groote Schuur Hospital, Cape Town, 2002 - 2009. S Afr Med J 2013;103(1):28-31. http://dx.doi.org/10.7196/samj.628

17. Zwi K, Pettifor J, Soderlund N, et al. HIV infection and in-hospital mortality at an academic hospital in South Africa. Arch Dis Child 2000;83(3):227-230. http://dx.doi.org/10.1136/adc.83.3.227

18. Zwi KJ, Pettifor JM, Soderlund N. Paediatric hospital admissions at a South African urban regional hospital: The impact of HIV, 1992 - 1997. Ann Trop Paed 1999:19(2):135-142. http://dx.doi.org/10.1080/02724939992455

19. Meyers T, Dramowski A, Schneider H, et al. Changes in paediatric HIV-related hospital admissions and mortality in Soweto, South Africa 1996 - 2011: Light at the end of the tunnel? J Acquir Immune Defic Syndr 2012;60(5):503-510. http://dx.doi.org/10.1097/qai.0b013e318256b4f8

20. Patrick ME, Stephen CR. Child PIP: Making mortality meaningful by using a structured mortality review process to improve the quality of care that children receive in the South African health system. S Afr J Child Health 2008;2(2):38-42.

21. Healthcare Cost and Utilization Project - United States. Clinical Classifications Software (CCS) for ICD10-CM/PCS. 2014. https://www.hcup-us.ahrq.gov/toolssoftware/ccs10/ccs10.jpp (accessed 30 January 2017).

22. Hon KE, Nelson EAS. Gender disparity in paediatric hospital admissions. Ann Acad Med Singapore 2006;35:882-888

23. Gissler M, Järvelin M-R, Louhiala $\mathrm{P}$, et al. Boys have more health problems in childhood than girls: Follow-up of the 1987 Finnish birth cohort. Acta Pædiatr 1999;88(3):310-314. http://dx.doi. org $/ 10.1080 / 0803525995017008$

24. Van den Bosch WJHM, Huygen FJA, van den Hoogen HJM, et al. Morbidity in early childhood: Differences between girls and boys under 10 years old. Br J Gen Pract 1992;42(362):366-369.

25. Madhi SA, Bamford L, Ngcobo N. Effectiveness of pneumococcal conjugate vaccine and rotavirus vaccine introduction into the South African public immunisation programme. S Afr Med J 2014;104(3):228-234. http://dx.doi.org/10.7196/SAMJ.7597

26. Msimang VMY, Page N, Groome MJ, et al. Impact of rotavirus vaccine on childhood diarrheal hospitalization after introduction into the South African public immunization program. Pediatr Infect Dis J 2013;32(12):1359-1364. http://dx.doi.org/10.1097/inf.0b013e3182a72fc0

27. Madhi SA, Groome MJ, Zar HJ, et al. Effectiveness of pneumococcal conjugate vaccine against presumed bacterial pneumonia hospitalisation in HIV-uninfected South African children: A case-control study. Thorax 2015;70(12):1149-1155. http://dx.doi.org/10.1136/thoraxjnl-2014-206593

28. Liu L Oza S, Hogan D, et al. Global, regional, and national trends of child mortality in 2000 - 2013, with projections to inform post-2015 priorities: An updated systematic analysis. Lancet 2015;385(9966):430440. http://dx.doi.org/10.1016/S0140-6736(14)61698-6

29. Barron P, Pillay Y, Doherty T, et al. Eliminating mother-to-child HIV transmission in South Africa. Bull World Health Organ 2013;91(1):70-74. http://dx.doi.org/10.2471/blt.12.106807

30. Harper K. An overview of Child PIP national data 2012 - 2013. In: Stephen CR, ed. Saving Children 2012 - 2013: An Eighth Survey of Child Healthcare in South Africa. Pretoria: Tshepesa Press, 2016:1-13.

31. Zühlke L, Mirabel M, Marijon E. Congenital heart disease and rheumatic heart disease in Africa: Recent advances and current priorities. Heart 2013;99(21):1554-1561. http://dx.doi.org/10.1136/ heartinl-2013-303896

32. Hesseling AC, Cotton MF, Jennings T. High incidence of tuberculosis among HIV-infected infants: Evidence from a South African population-based study highlights the need for improved tuberculosis control strategies. Clin Infect Dis 2009;48(1):108-114. http://dx.doi.org/10.1086/595012

33. Madhi SA, Huebner, RE, Doedens L, et al. HIV-1 co-infection in children hospitalised with tuberculosis in South Africa. Int J Tuberc Lung Dis 2000;4(5):448-454.

34. Groenewald P, Evans J, Morden E, et al. Western Cape Mortality Profile 2012. Cape Town: South African Medical Research Council, 2015.

35. O'Malley KJ, Cook KF, Price MD, et al. Measuring diagnoses: ICD code accuracy. Health Services Research 2005;40(5):1620-1639. http://dx.doi.org/10.111//.1475-6773.2005.00444.x

Accepted 13 January 2017 